\title{
A New Species of Australian Funnel-web Spider (Mygalomorphae, Atracidae, Hadronyche) Redefines the Family Atracidae
}

\author{
Paul M. Whitington (iD And Kerri-Lee Harris (D) \\ Department of Anatomy and Physiology, \\ University of Melbourne, Parkville VIC 3010, Australia
}

\begin{abstract}
We describe a new and unusual species of funnel-web spider from the far south coast of New South Wales. Hadronyche nadgee sp. nov. has only a single row of cheliceral teeth, a condition unique among known atracids. All Atrax, Illawarra, and Hadronyche species described to date have teeth on both sides of the cheliceral groove. Moreover, a retromarginal row of large teeth has been one of the diagnostic features of the Atracidae. Hadronyche nadgee sp. nov. has only a promarginal row. We therefore amend the diagnosis of the family to accommodate this new species, which in all other ways meets the criteria for Hadronyche (Atracidae).
\end{abstract}

\section{Introduction}

Funnel-web spiders are an iconic Australian taxon. Their fame and notoriety can be attributed to a single species, the Sydney funnel-web spider (Atrax robustus O. P.Cambridge, 1877), which has been responsible for many serious envenomations, including numerous deaths prior to the development of an antivenom in 1980 (Nicholson et al., 2006).

In his major revision of funnel-web spiders, Gray (2010) placed this group in a subfamily Atracinae of the family Hexathelidae. Gray recognized three genera-Atrax O. P.Cambridge, 1877; Hadronyche L. Koch, 1873; Illawarra Gray, 2010 - across the 35 atracine species and defined diagnostic characters separating them from their sister group, the Hexathelinae. More recently, a molecular study of all described hexathelid genera and a sample of related mygalomorphs elevated the atracid spiders to family level (Hedin et al., 2018). The remaining hexathelids were split into several families-Hexathelidae, Porrhothelidae and Macrothelidae. This molecular analysis placed the Actinopodidae, mouse spiders, as the sister group of the Atracidae.

Gray (2010) speculated that there are likely to be many undescribed atracid species. However, since his revision no new species have been published.

We describe here a new funnel-web spider from the far south coast of New South Wales. The species shares a number of morphological characters with some members of the Hadronyche species group lamingtonensis Gray, 2010. However, it displays several features that distinguish it from those species and indeed all other atracid spiders, prompting a redefinition of the diagnosis for Atracidae.

Only roaming males of this species have been found to date and these were encountered on rainy nights in late Autumn to mid Winter. This habit, together with the relatively small size of the spider, may account for it remaining undiscovered until now. 


\section{Materials and methods}

All type specimens were collected live on private land, with permission, and preserved within 24 hours in $85-100 \%$ ethanol.

Photographs were taken with an Olympus OM-D E-M1 camera either fitted with an Olympus $60 \mathrm{~mm}$ f 2.8 macro lens or mounted on a Zeiss Tessovar macrophotography rig. Scale bar sizes were calculated by photographing a stage micrometer at the same magnification as the specimen. All measurements are given in millimetres and are rounded to the nearest $0.05 \mathrm{~mm}$. Spines and cuspules were counted both directly under a Zeiss SR stereomicroscope at 20-50× magnification and from photographic images.

Image processing (cropping, exposure adjustment, focal plane stacking) was done with Adobe Photoshop Lightroom Classic (Adobe Systems Inc., San Jose, CA, USA).

\section{Notes on descriptions}

For ease of comparison, the layout of the species description is based on that used by Gray (2010) in his revision of the family. Measurements of individual body parts were made as shown by Gray (2010: appendix 1). For paired appendages, the left side is used for all measurements and morphological descriptions.

Spines were distinguished from hairs by the following features: thicker; shorter; not as curved. Leg spine counts are given as the total count per leg segment. Most leg spines are ventral or ventrolateral. Any dorsal (d), prolateral (p) or retrolateral ( $\mathrm{r}$ ) spines are given in parentheses after the total count. Patella spine counts include total ventral and prolateral dorsal spines.

\footnotetext{
Abbreviations

Morphology: ALE, anterior lateral eye; AME, anterior median eye; PLE, posterior lateral eye; PME, posterior median eye; $\mathrm{CL}$, carapace length; $\mathrm{CW}$, carapace width; $\mathrm{CFW}$, clypeal frontal width; $\mathrm{CH}$, carapace height; LL, labium length; LW, labium width; SL, sternum length; SW, sternum width; PLS, posterior lateral spinneret.

Repository institutions: Australian Museum, Sydney and Queensland Museum, Brisbane.

Specimen registration codes: AMS KS, prefix of Australian Museum, Sydney register numbers; QMS, prefix of Queensland Museum, Brisbane, register numbers.
}

\section{Systematics}

\section{Family Atracidae Hogg, 1901}

Included genera: Atrax O. P.-Cambridge, 1877; Hadronyche L. Koch, 1873; Illawarra Gray, 2010.

Diagnosis (modified from Gray, 2010). Atracidae can be distinguished from other mygalomorph spiders by the combination of the following characters: only 2 pairs of spinnerets, a relatively broad embolic shaft, large posterior sternal sigilla, maxillae with coniform anterior lobe, PLS relatively short, fovea a transverse groove.

Remarks. In his diagnosis for Atracinae (subsequently elevated to family status by Hedin et al., 2018), Gray (2010: 290) included the character "cheliceral retromargin with row of large teeth". The absence of teeth on the cheliceral retromargin of $H$. nadgee sp. nov. requires removal of this feature from the diagnosis for family Atracidae.

\section{Hadronyche L. Koch, 1873}

Hadronyche L. Koch, 1873: 463. Type species by original designation and monotypy, Hadronyche cerberea L. Koch, 1873.

Diagnosis (from Gray, 2010). Tibia II either unmodified or with a blunt, rounded apophysis or apophyseal swelling; caput moderately to strongly raised and cheliceral paturon robust; male tarsi with two ventral spine rows.

Remarks. The 31 existing Hadronyche spp. show a substantial degree of diversity. Characters that vary across the genus include: number of cheliceral teeth, particularly in the central row; shape of labium and number of labial cuspules; relative width of palpal patella and femur; shape of apical segment of the PLS; modification of leg II; and shape of tarsi on legs III and IV (Raven, 2000; Gray, 2010). Gray (2010) divided the genus into four species groups based on these and other characters. The most morphologically distinctive of these groups is lamingtonensis.

\section{Hadronyche nadgee sp. nov.}

urn:Isid:zoobank.org:act:71E46225-1221-490B-A415-53E7C98C4661

\section{Figs $1-5$}

Holotype male: AMS KS.131058 Wonboyn, New South Wales, 37¹4'38"S 149 $54^{\prime} 11^{\prime \prime E}$, 9 June 2021. K.-L. Harris \& P. Whitington. Paratypes (all adult males, same location and collector data as for holotype, but with different dates as follows): AMS KS.131059, AMS KS.131060, QMS 116530, QMS 116531, 22 May 2020; AMS KS.131061, 14 June 2020; AMS KS.131062, 3 June 2021; AMS KS.131063, AMS KS.131064, 9 June 2021.

Other material examined: (male) AMS KS.105558, SE Forests National Park, New South Wales, $10 \mathrm{~km} \mathrm{~W}$ of Brogo end of Dorrigo Road, 338 m, 16 June 2006, C. A. Car. 

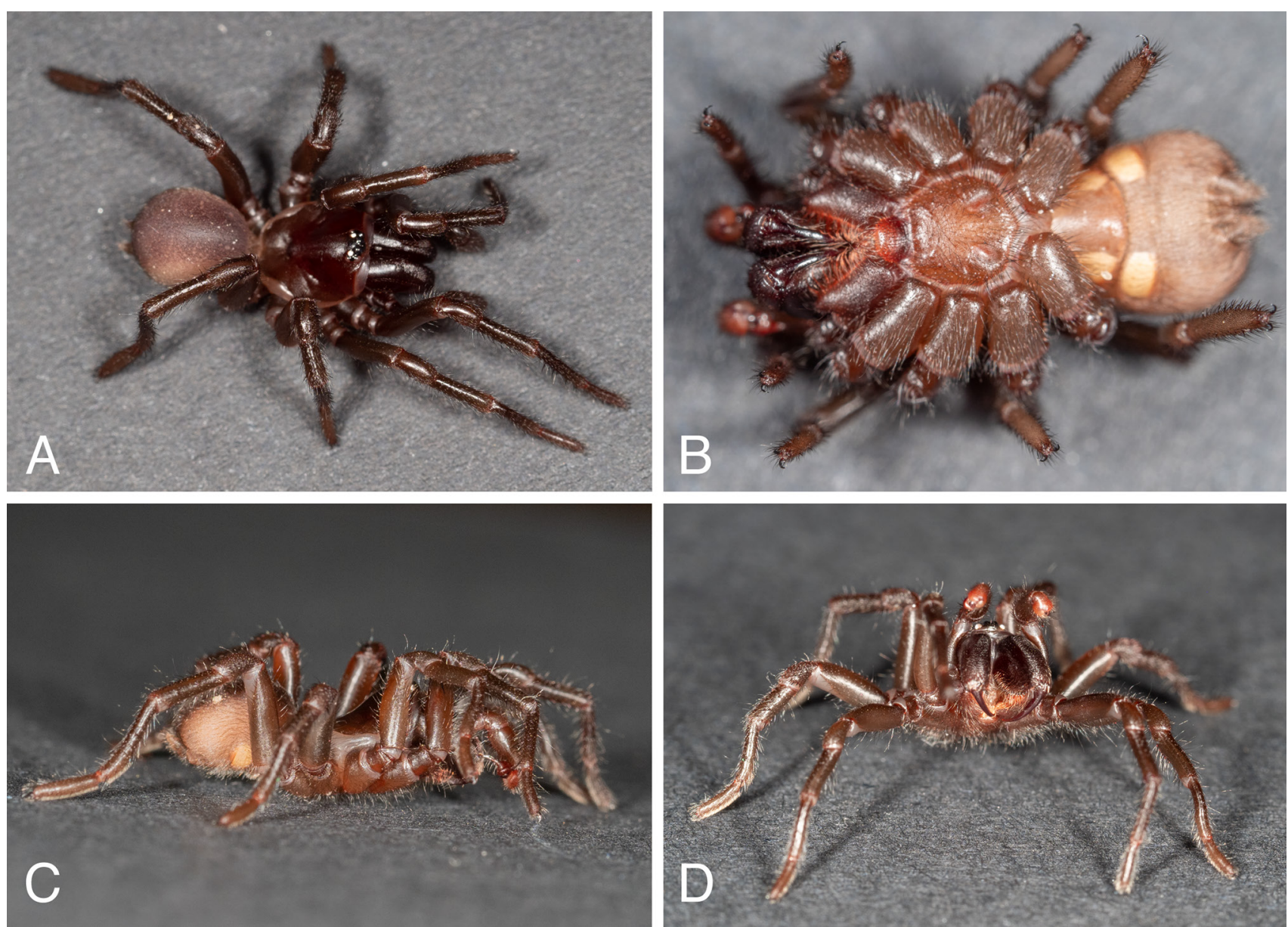

Figure 1. Hadronyche nadgee sp. nov., male (A, holotype AMS KS.131058; B, C, D, AMS KS.131064): $(A)$ live, dorsal; $(B)$ live and in "play dead" pose, ventral; $(C)$ live, lateral; $(D)$ live and in defensive pose, anterior.

\section{Diagnosis}

CL 3.85-4.80 (male). Small atracine spider. Differs from all other Hadronyche spp. in having a single row of 8-10 cheliceral teeth on promargin and no teeth along retromargin (Fig. 3A). Labium with a sparse cluster of cuspules (20-39) over anteroventral two-thirds (Fig. 3D). Females unknown.

\section{Description (holotype male)}

Size (mm). Carapace length 4.40, width 3.70. Abdomen length 3.70 , width 2.80 .

Colour (live). Carapace and legs chocolate brown. Chelicerae very dark brown. Abdomen ventrally and laterally pinkish brown. Abdomen dorsally has wide central plum-brown band with numerous small, unpigmented dots arranged in a regular pattern. Abdomen with a thin, even cover of short, dark hairs on all surfaces. (alcohol preserved): Carapace and chelicerae orange-brown, legs yellow-brown. Abdomen ventrally and laterally pale with a broad, plum-coloured, dorsal medial band.

Carapace. Longer than wide. Frontal width 3.20, height 2.50. Sparsely haired. Caput strongly raised $(\mathrm{CH} / \mathrm{CW} 0.68)$ and broad frontally (CFW/CL 0.73). Caput spans the anterior edge of the carapace. Fovea a transverse, procurved groove. Clypeus with cluster of 10-12 short bristles centrally, and one long bristle between AME. Pleura widest in line with fovea and coxae of leg III. Relative to the carapace width, pleurae are wider than in most other atracids (refer figures in Gray, 2010).

Eyes. In rectangular group on low tubercle, in two rows of four. Eye group length 0.60 , width 1.20. Diameters: AME 0.30, ALE 0.30, PME 0.20, PLE 0.25.

Chelicerae. Robust cheliceral paturon. Cheliceral groove shallow. Single row of 9 cheliceral teeth along promargin (medial) of each paturon. No teeth along retromargin. Cluster of 3 small central teeth at base of groove.

Maxillae. Longer than wide. Strong coniform lobe anteromedially. Numerous cuspules (38) in medioventral region.

Labium. Wider than long (LL/LW 0.65). Sparse cluster of cuspules (32) over anteroventral two-thirds. Labiosternal sigilla wide and complete.

Sternum. Ovoid, longer (2.40) than wide (SW/SL 0.88). Posterior sigillae ovoid. Two anterior pairs of sigillae, smaller and indistinct.

Palps. Cymbium bilobed. Subtegulum smaller than tegulum. Middle haematodocha exposed. Embolus shaft weakly curved, medium length, flattened and twisted distally. Bulb length 1.10, width 0.55. Embolus length 0.70, midwidth 0.10. 

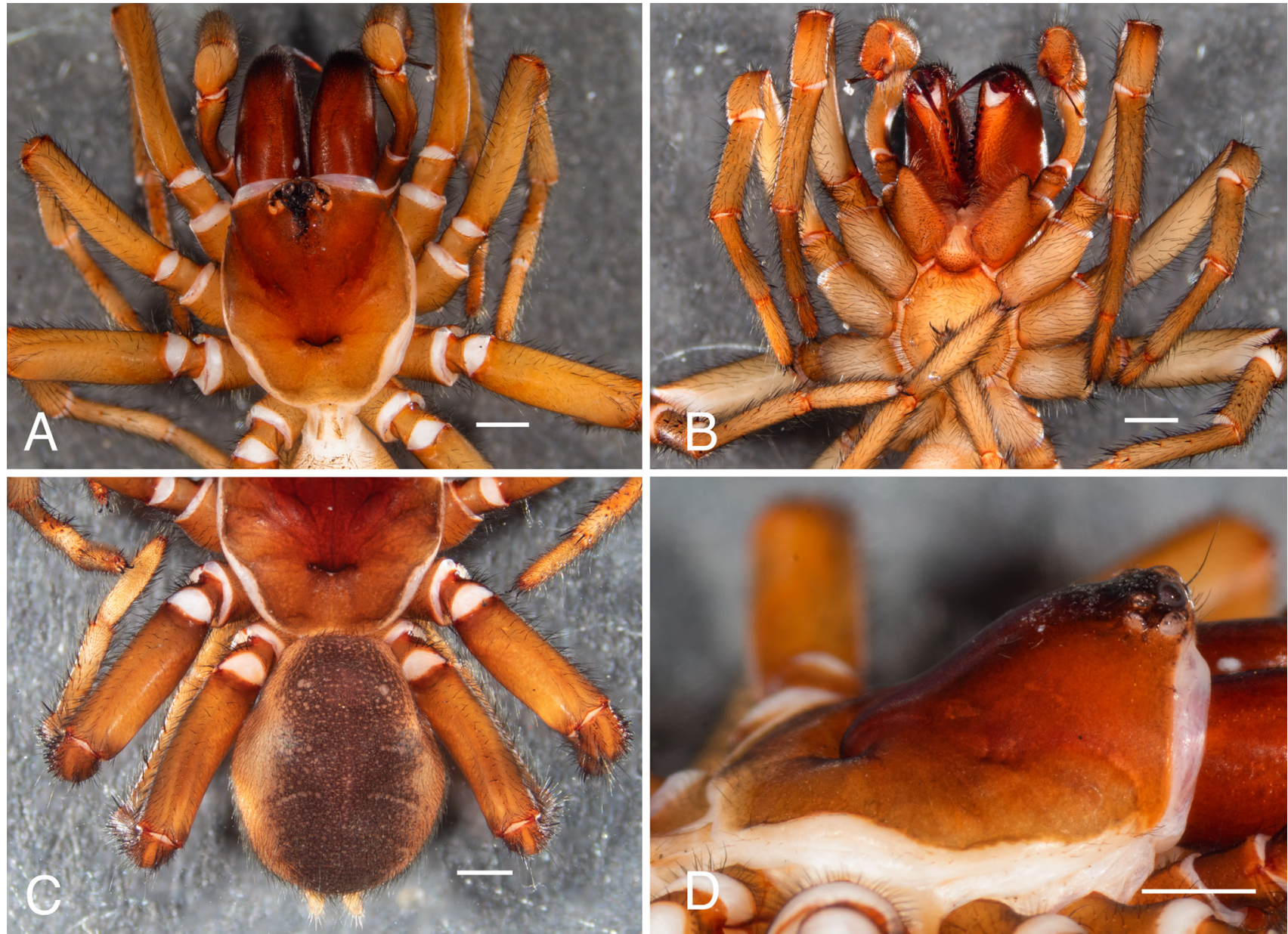

Figure 2. Hadronyche nadgee sp. nov., male (A, B, D, holotype AMS KS.131058; C, AMS KS.131062): (A) cephalothorax, chelicerae, proximal segments of palps and legs I-III, dorsal; $(B)$ sternum, leg bases, ventral mouthparts, palps, and chelicerae, ventral; $(C)$ abdomen, fovea, femora legs III-IV, dorsal; $(D)$ carapace, caput, eye group and clypeus, lateral. Scale lines A-C $=1 \mathrm{~mm}, \mathrm{D}=0.5 \mathrm{~mm}$

Femur thickened distally. Patella much wider than femur. Width of femur 0.60 , patella 0.85 , tibia 0.75 . Length of femur 1.70 , patella 1.00, tibia 1.90. Tibia without apophysis. Femur, patella and tibia aspinose.

Legs. 412-3. Lengths given in Table 1. Metatarsus I unmodified. Tibia II unmodified. Metatarsus II weakly sinuous, ventrally concave proximally, with slight apophyseal swelling. Tarsi III, IV longer and wider than tarsi I, II. Tarsus IV thickest in the distal mid section. Scopulae on ventral surface of all tarsi. Tarsi III, IV with wide band of thick, bent scopular hairs extending onto metatarsus. Scopulae weaker on tarsi I, II.

Tarsal claws. Tip of each tarsus bears 3 claws: a large superior pair and a smaller medial claw. Superior claws of legs I and II each with single row of 7-9 teeth of various sizes. The tooth row sigmoidal, extending from lateral (proximally) to medial edge (distally).
Trichobothria. Leg I: tibia 8, metatarsus 6, tarsus 6. Leg II: tibia 6, metatarsus 5, tarsus 6. Leg III: tibia 6, metatarsus 5, tarsus 8. Leg IV: tibia 9, metatarsus 7, tarsus 10. Palps: cymbium 4 , tibia 8 .

Leg spination. Spines on tarsi of all legs in two rows on either side of the scopula. Leg I: femur 0, patella 0, tibia 7, metatarsus 10, tarsus 5. Leg II: femur 0 , patella 0 , tibia 4, metatarsus 9, tarsus 6. Leg III: femur 0, patella 31 (p28 r3), tibia 6 (d1 p3 r1), metatarsus 14 (d5 p4), tarsus 7. Leg IV: femur 0 , patella 12 (p12), tibia 5 (d1 p2), metatarsus 22 (d1 p3), tarsus 29.

Abdomen. Two pairs of spinnerets. Lateral pair (PLS) separated by more than width of basal segment, and with short, conical apical segment. PLS segment lengths: total 1.25 , basal 0.55 , middle 0.30 , apical 0.40 . PLS apical segment width 0.25 . Median spinnerets each comprising a single segment: length 0.40 , width 0.20 .

Table 1. Leg measurements (mm) of Hadronyche nadgee sp. nov., holotype (male) AMS KS.131058.

\begin{tabular}{ccccccc}
\hline leg & femur & patella & tibia & metatarsus & tarsus & total \\
\hline I & 3.65 & 1.50 & 2.55 & 2.40 & 1.80 & 11.90 \\
II & 3.40 & 1.30 & 2.25 & 2.55 & 1.70 & 11.20 \\
III & 3.30 & 1.55 & 1.90 & 2.50 & 2.00 & 11.25 \\
IV & 3.65 & 1.65 & 2.85 & 3.30 & 2.40 & 13.85 \\
\hline
\end{tabular}



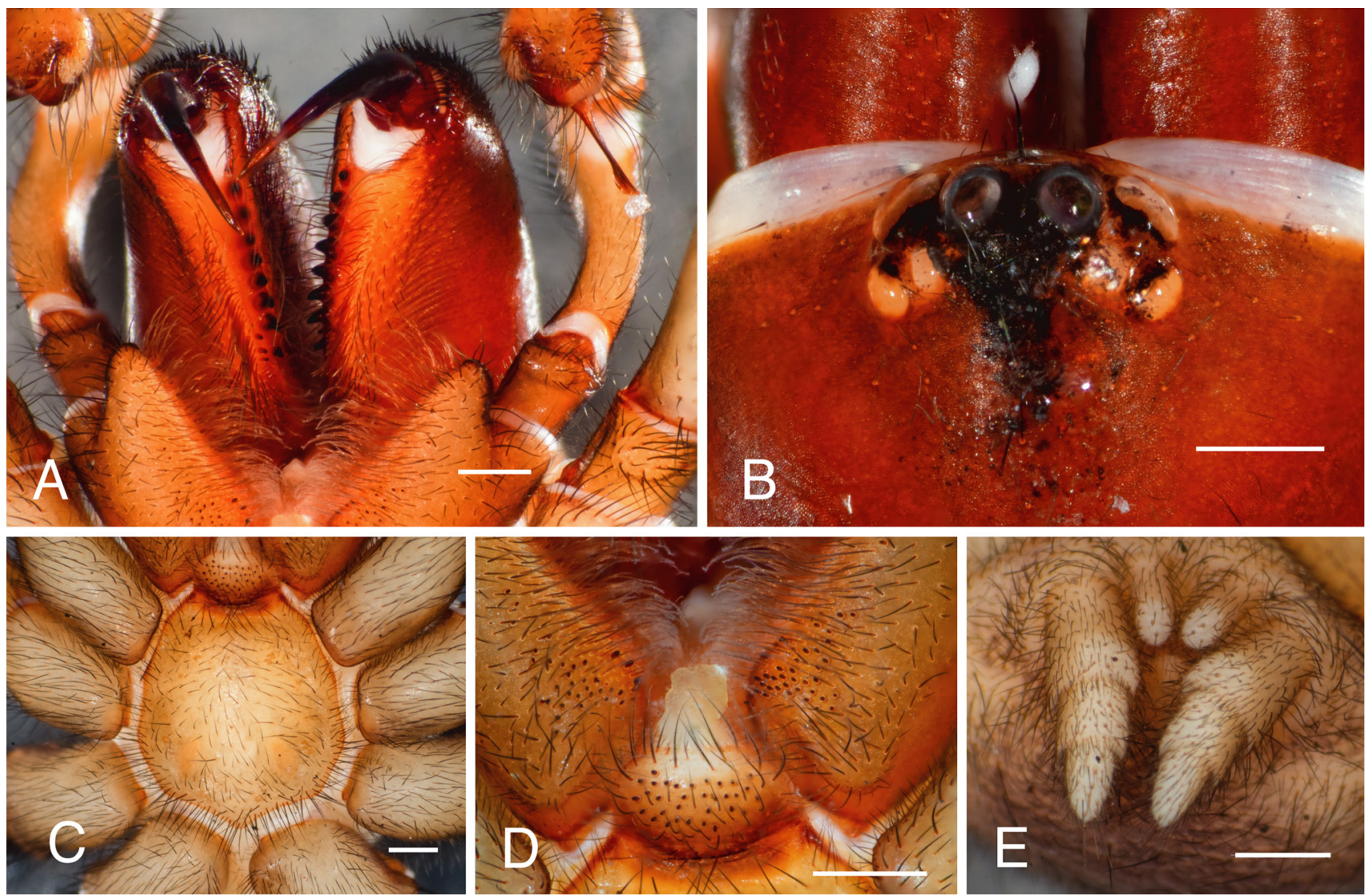

Figure 3. Hadronyche nadgee sp. nov., male (all holotype AMS KS.131058): (A) cheliceral groove teeth, fangs and apical lobes of maxillae, ventral; $(B)$ eyes and clypeus, dorsal; $(C)$ sternum, ventral; $(D)$ labium and base of maxillae, ventral; $(E)$ spinnerets, posteroventral. Scale lines $=0.5 \mathrm{~mm}$.

A summary of morphological data for the nine type specimens, all male and including the holotype, is presented in Table 2.

Distribution. "South East Coastal Ranges", a subregion of the South East Corner IBRA bioregion (Australian Government, 2012).

Etymology. The name nadgee is a noun in apposition taken from the Nadgee Nature Reserve, the northwestern boundary of which is just $2 \mathrm{~km}$ from the type location.

\section{Comments}

All nine type specimens were discovered wandering at or near ground level on wet, cool nights (measured as $11^{\circ} \mathrm{C}$ on two occasions) in late Autumn and early Winter. The collection site for the holotype and eight paratypes is near the village of Wonboyn, $5 \mathrm{~km}$ from the coast in an area of dry sclerophyll forest classed as Lowland Gully Shrub Forest (Keith \& Bedward, 1999; Tozer et al., 2010).

Upon collection these spiders were quite passive. When provoked, all except one simply rolled over and adopted a "play dead" pose (Fig. 1B). After a day in captivity, however, they became much more reactive. At the least provocation they would rear back with pedipalps raised and fangs exposed (Fig. 1D). One of the spiders wove a silken retreat overnight within a fold of moistened paper.

The other male (AMS KS.105558) examined was also collected in early Winter, also from a forest environment, but $25 \mathrm{~km}$ from the coast.

\section{Discussion}

Hadronyche nadgee sp. nov. displays most of the diagnostic characters of Atracidae, which in combination exclude it from any of the other mygalomorph families. However, $H$. nadgee differs from all previously described atracid species in one key feature.

All other Atracidae have a cheliceral groove flanked by two rows of large teeth and a middle region of smaller teeth (Gray, 2010). The number of teeth in each row can vary, and in the case of $H$. anzses Raven, 2000 the promarginal row is reduced to just three teeth (Raven, 2000), but in all currently described species there is both a promarginal and a retromarginal row. In $H$. nadgee the retromarginal row is completely absent (Fig. 3A). This difference has led us to redefine the Atracidae by excluding mention of cheliceral teeth from the family diagnosis.

Hadronyche nadgee possesses a number of features that justify its placement in Hadronyche and separate it from the other atracine genera, Atrax and Illawarra. Tibia II lacks the modifications (Fig. 5C, D) found in Atrax spp. and the third row of spines seen on the ventral side of the tarsi (Fig. 5F) of Illawarra wisharti Gray, 2010 (Gray, 2010). In addition, the caput (Fig. 2D) is more strongly raised than in Atrax and Illawarra spp., although it should be noted that this character shows substantial variation in $H$. nadgee $(\mathrm{CH} / \mathrm{CW}$ range 0.47-0.68).

Hadronyche nadgee possesses a number of morphological features shared by species in the lamingtonensis group of Hadronyche. These include small body size, short and wide 

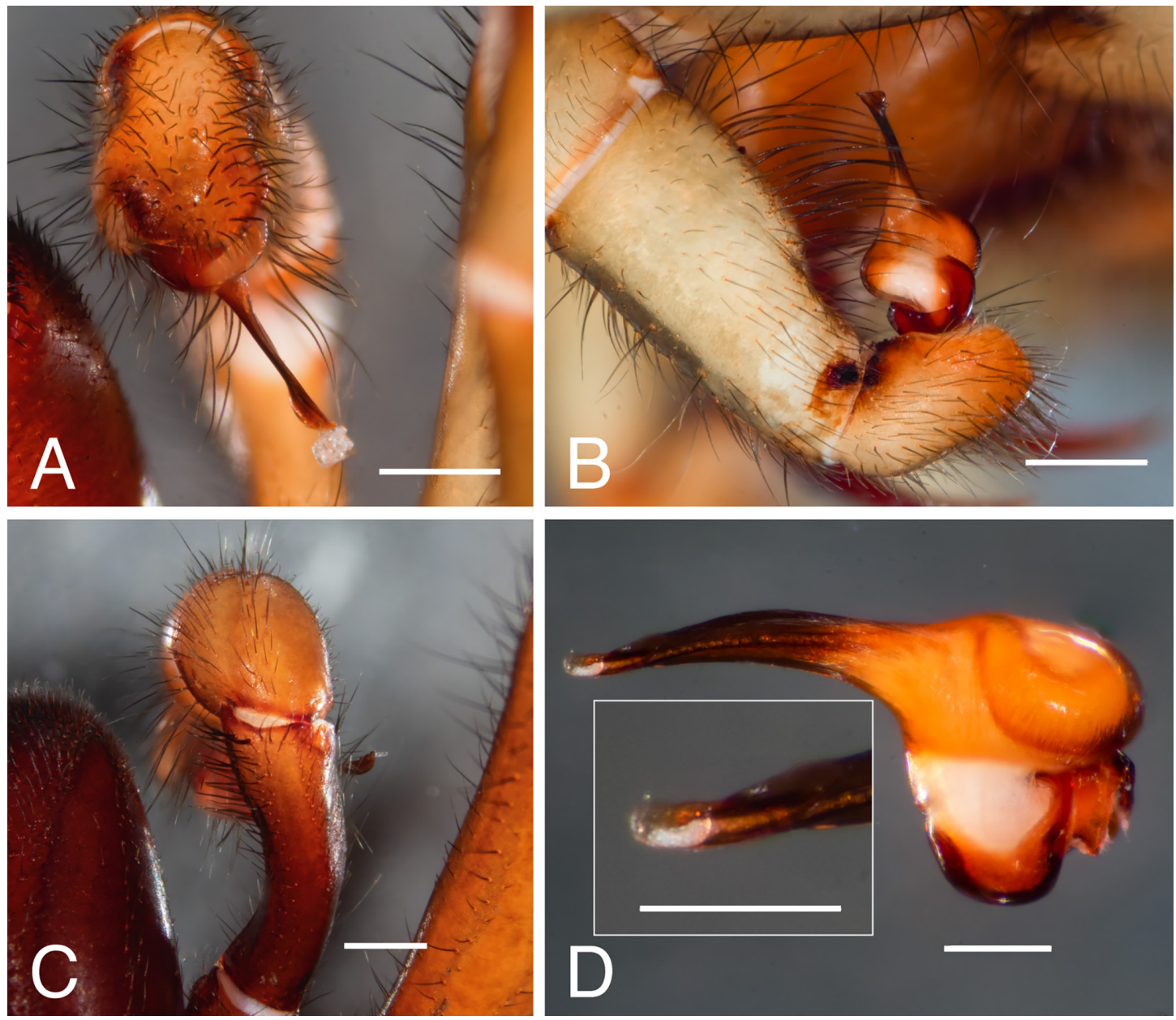

Figure 4. Hadronyche nadgee sp. nov., male (A, holotype AMS KS.131058; B, AMS KS.131059; C, AMS KS.131062; D, AMS KS.131061): $(A)$ palpal cymbium and bulb, left, anterodorsal; $(B)$ palpal tibia, cymbium and bulb, right retrolateral; $(C)$ palpal femur and patella, right, dorsal; $(D)$ bulb removed from left palp, inset shows distal tip of embolus. Scale lines $=0.5 \mathrm{~mm}$, except D and D inset $=0.2 \mathrm{~mm}$.

Table 2. Male morphological data-Hadronyche nadgee sp. nov. $(\mathrm{n}=9)$.

\begin{tabular}{|c|c|c|c|c|c|c|c|c|}
\hline character & range & mean & character & range & mean & character & ratio & $\mathrm{SD}$ \\
\hline CL & $3.85-4.80$ & 4.31 & PLSAPW & $0.20-0.30$ & 0.26 & $\mathrm{CW} / \mathrm{CL}$ & 0.87 & 0.024 \\
\hline $\mathrm{CW}$ & $3.40-4.30$ & 3.76 & Fe1S & 0 & 0 & $\mathrm{CH} / \mathrm{CW}$ & 0.56 & 0.061 \\
\hline $\mathrm{CH}$ & $1.85-2.50$ & 2.10 & $\mathrm{~Pa} 1 \mathrm{~S}$ & 0 & 0 & $\mathrm{CFW} / \mathrm{CL}$ & 0.69 & 0.022 \\
\hline CFW & $2.70-3.30$ & 2.99 & Ti1S & $3-8$ & 5 & $\mathrm{SW} / \mathrm{SL}$ & 0.89 & 0.048 \\
\hline ChGL & $1.05-1.35$ & 1.17 & Mt1S & $8-11$ & 9 & LL/LW & 0.64 & 0.031 \\
\hline ChGPT & $8-10$ & 9 & Ta1S & $4-6$ & 5 & PLSAPW/L & 0.84 & 0.168 \\
\hline ChGRT & 0 & 0 & Ti2S & $2-5$ & 4 & PalpTibW/L & 0.45 & 0.046 \\
\hline ChGCT & 2-10 & 5 & STC2teeth & $8-9$ & 8 & & & \\
\hline LL & $0.50-0.70$ & 0.58 & PalpFemS & 0 & 0 & & & \\
\hline LW & $0.80-1.05$ & 0.89 & PalpPatS & 0 & 0 & & & \\
\hline CUSP & 20-39 & 29 & PalpTibS & 0 & 0 & & & \\
\hline SL & $2.10-2.70$ & 2.39 & PalpTibL & $1.50-1.90$ & 1.73 & & & \\
\hline SW & $1.90-2.45$ & 2.12 & PalpTibW & $0.75-1.00$ & 0.81 & & & \\
\hline PLSAPL & $0.20-0.40$ & 0.32 & & & & & & \\
\hline
\end{tabular}

ChGL, cheliceral groove length; ChGPT, cheliceral groove promarginal row teeth number; ChGRT, cheliceral groove retromarginal row teeth number; ChGCT, cheliceral groove central row teeth number; CUSP, labium cuspule number; PLSAPL, posterior lateral spinneret apical segment length; PLSAPW, posterior lateral spinneret apical segment width; Fe1S, femur I spine number; Pa1S, patella I spine number; Ti1S, tibia I spine number; Mt1S, metatarsus I spine number; Ta1S, tarsus I spine number; Ti2S, tibia II spine number; STC2teeth, number of teeth on tarsus II superior claws; PalpFemS, male palpal femur spine number; PalpPatS, male palpal patella spine number; PalpTibS, male palpal tibia spine number; PalpTibL, male palpal tibia length; PalpTibW, male palpal tibia width. 

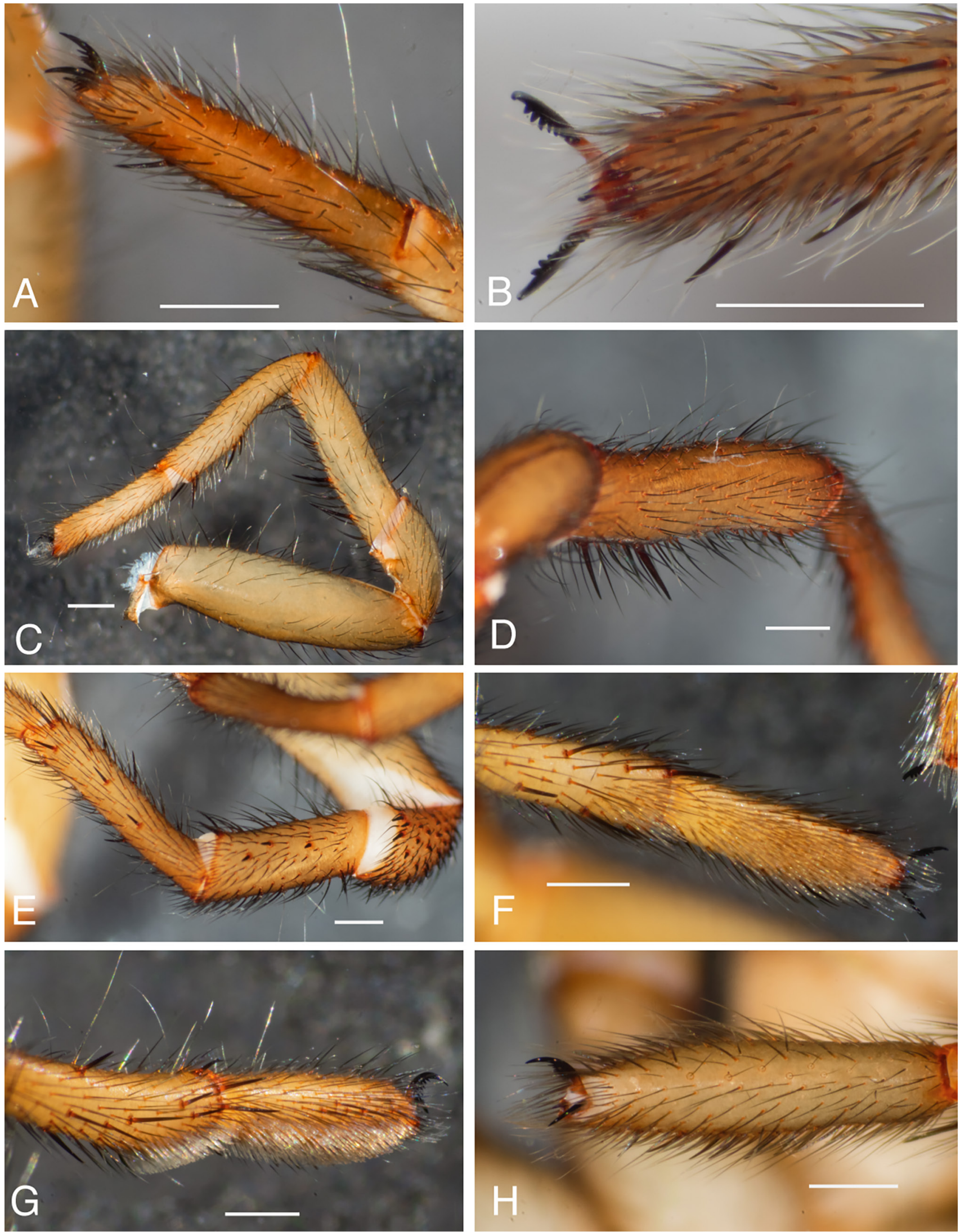

Figure 5. Hadronyche nadgee sp. nov., male (A, H, AMS KS.131059; B, F, G, AMS KS.131063; C, AMS KS.131061; D, AMS KS.131064; E, holotype AMS KS.131058): (A) tarsus I, right leg, dorsal; $(B)$ distal tarsus II, ventral; $(C)$ femur, patella, tibia, metatarsus, tarsus, left leg II, prolateral; (D) tibia II, right leg, retrolateral; $(E)$ patella, tibia, metatarsus III, left leg, prolateral; $(F)$ distal metatarsus and tarsus III, left leg, ventral; $(G)$ distal metatarsus and tarsus IV, left leg, prolateral; $(H)$ tarsus IV, right leg, dorsal. Scale lines $=0.5 \mathrm{~mm}$ 
labium with a low cuspule count (Fig. 3D), shape of tarsi III and IV (Fig. 5F-H) and wide pleurae (Figs 1A, 2A, D)compare with pleurae in H. lamingtonensis (Gray, 2010: fig. 97G) and $H$. anzses (Raven, 2000: fig. 1A, C). Future molecular studies may help to clarify relationships within this morphologically diverse genus.

Acknowledgements. We thank Dr Robert Raven, Queensland Museum, for sharing his observations and data of a previously unidentified museum specimen of $H$. nadgee (AMS KS.105558). The work also benefited from feedback and constructive comments received from Dr Helen Smith, Australian Museum.

\section{References}

Australian Government. 2012. Interim Biogeographical Regionalisation for Australia, Version 7. Australian Government Department of Agriculture, Water and the Environment, and State/ Territory land management agencies. Maps and region codes. https://environment.gov.au/land/nrs/science/ibra
Gray, M. R. 2010. A revision of the Australian funnel-web spiders (Hexathelidae: Atracinae). Records of the Australian Museum 62(3): 285-392.

https://doi.org/10.3853/j.0067-1975.62.2010.1556

Hedin, M., S. Derkarabetian, M. J. Ramírez, C. Vink, and J. E. Bond. 2018. Phylogenomic reclassification of the world's most venomous spiders (Mygalomorphae, Atracinae), with implications for venom evolution. Scientific Reports 8: 1636. https://doi.org/10.1038/s41598-018-19946-2

Keith, D. A., and M. Bedward. 1999. Native vegetation of the South East Forests region, Eden, New South Wales. Cunninghamia 6(1): $1-218$.

https://www.rbgsyd.nsw.gov.au/Science/Our-work-discoveries/Scientific-publications/ Cunninghamia

Nicholson, G. M., A. Graudins, H. I. Wilson, M. Little, and K. W. Broady. 2006. Arachnid toxicology in Australia: from clinical toxicology to potential applications. Toxicon 48(7): 872-898. https://doi.org/10.1016/j.toxicon.2006.07.025

Raven, R. J. 2000. A new species of funnel-web spider (Hadronyche: Hexathelidae: Mygalomorphae) from north Queensland. Memoirs of the Queensland Museum 46(1): 225-230.

Tozer, M. G., K. Turner, D. A. Keith, D. Tindall, C. Pennay, C. Simpson, B. MacKenzie, P. Beukers, and S. Cox. 2010. Native vegetation of southeast NSW: a revised classification and map for the coast and eastern tablelands. Cunninghamia 11(3): 359-406. https://www.rbgsyd.nsw.gov.au/Science/Our-work-discoveries/Scientific-publications/ Cunninghamia 